\title{
ROPN1 Positive
}

National Cancer Institute

\section{Source}

National Cancer Institute. ROPN1 Positive. NCI Thesaurus. Code C142843.

An indication that ROPN1 expression has been detected in a sample. 